Pacific Journal of Mathematics

INVERTING OPERATORS FOR SINGULAR BOUNDARY VALUE 


\title{
INVERTING OPERATORS FOR SINGULAR BOUNDARY VALUE PROBLEMS
}

\author{
C. L. IRWIN
}

Let $S$ denote a Banach Space, $B$ the bounded linear transformations on $S$, and let $Q$ and $A$ denote functions from $[0, \infty)$ into $B$ with $Q$ continuous. The objective here is to derive a Green's function $K_{A}$ and hence an integral inverting operator $R_{A}$ for the singular boundary value problem

$$
\left\{\begin{array}{l}
Y^{\prime}-Q Y=H \\
A(\mathbf{0}) Y(\mathbf{0})+\lim _{n \rightarrow \infty} A\left(c_{n}\right) Y\left(c_{n}\right)=\mathbf{0},
\end{array}\right.
$$

where $\left\{c_{n}\right\}_{n=1}^{\infty}$ is a positive, increasing, unbounded number sequence and $H$ is a continuous function from $[0, \infty)$ into $S$.

The method here provides Green's functions for singular boundary value problems associated with nonself-adjoint, as well as self-adjoint, linear differential expressions. The asymptotic boundary conditions in (1) permit one to extend some of the regular two-point boundary value problem techniques suggested by [3] and [4] to the singular case without being restricted to the Hilbert Space $L_{2}[0, \infty)$. Similar, but different, asymptotic boundary conditions are used by Coddington and Levinson in [2, Chapter 10], and by Benzinger [1].

As noted in $\S 3$ of [3] there exists a unique continuous function $M$ from $[0, \infty) \times[0, \infty)$ to $B$ so that if each of $x, t$, and $u$ is in $[0, \infty)$,

(i ) $M_{1}(x, t)=Q(x) M(x, t)$ and $M(t, t)=I$

(ii) $M(x, t) M(t, u)=M(x, u)$

(iii) if $H$ is a continuous function from $[0, \infty)$ to $S$ and $\alpha$ is in $S$, then the only function $Y$ such that $Y^{\prime}-Q Y=H$ and $Y(0)=\alpha$ is given by

$$
Y(x)=M(x, 0) \alpha+\int_{0}^{x} d t M(x, t) H(t)
$$

for all $x$ in $[0, \infty)$.

Definition. $A$ is a determinate boundary condition function for $Q$ on $c_{1}, c_{2}, \cdots$ means that if $H$ is a continuous function on $[0, \infty)$ and $Y$ is a solution of the boundary value problem (1) for the nonhomogeneous term $H$, then $Y$ is unique.

Notation. If $A$ is a boundary condition function for $Q$ on $c_{1}$, $c_{2}, \cdots$ and $n$ is a positive integer, let $T_{n}$ denote the transformation 
$\left[A(0)+A\left(c_{n}\right) M\left(c_{n}, 0\right)\right]$.

THEOREM 1. A is a determinate boundary condition function for $Q$ on $c_{1}, c_{2}, \ldots$ if and only if the convergence of $\left\{T_{n} \alpha\right\}_{n=1}^{\infty}$ to zero implies that $\alpha$ is the zero of $S$.

Proof. The proof follows from property (iii) of the $M$ function and the linearity of the problem.

Notation. Let $D_{0}$ denote the continuous functions with compact support on $[0, \infty)$.

THEOREM 2. Suppose $A$ is a determinate boundary condition function for $Q$ on $c_{1}, c_{2}, \cdots$; the following two statements are equivalent.

(i) There is an integral inverting operator $R_{A}$ with kernel $K_{A}$ of the form

$$
K_{A}(x, t)= \begin{cases}M(x, 0) K_{A}(0,0) M(0, t) & \text { if } 0 \leqq t \leqq x \\ M(x, 0)\left[K_{A}(0,0)-I\right] M(0, t) & \text { if } 0 \leqq x<t\end{cases}
$$

for boundary value problem (1) so that $D_{0}$ is a subset of the domain of $R_{A}$.

(ii) There is a transformation $\pi$ in $B$ such that if $\alpha$ is in $S$, then $\left\{T_{n}(\pi \alpha)\right\}_{n=1}^{\infty}$ converges to $A(0) \alpha$.

Proof. Assume ( i ) holds; if $H$ is in $D_{0}$ and $U=R_{A} H$, then $U$ is a solution of boundary value problem (1) and so

$$
\lim _{n \rightarrow \infty}\left[A(0) U(0)+A\left(c_{n}\right) U\left(c_{n}\right)\right]=0 .
$$

Let $b$ denote a positive number so that if $x>b, H(x)=0$; then, if $c_{n}>b$,

$$
\begin{aligned}
A(0) U(0)+A\left(c_{n}\right) U\left(c_{n}\right)= & A(0) \int_{0}^{b} d t\left[K_{A}(0,0)-I\right] M(0, t) H(t) \\
& +A\left(c_{n}\right) \int_{0}^{b} d t M\left(c_{n}, 0\right) K_{A}(0,0) M(0, t) H(t) \\
= & T_{n}\left(K_{A}(0,0) \int_{0}^{b} d t M(0, t) H(t)\right) \\
& -A(0) \int_{0}^{b} d t M(0, t) H(t)
\end{aligned}
$$

and so 


$$
\lim _{n \rightarrow \infty} T_{n}\left(K_{A}(0,0) \int_{0}^{b} d t M(0, t) H(t)\right)=A(0) \int_{0}^{b} d t M(0, t) H(t) .
$$

Now, if $\alpha$ is in $S$, define $H$ as

$$
H(t)=\left\{\begin{array}{lr}
M(t, 0)(2-2 t) \alpha & \text { if } 0 \leqq t \leqq 1 \\
0 & \text { if } t>1
\end{array}\right.
$$

$H$ belongs to $D_{0}$ and $\int_{0}^{b} d t M(0, t) H(t)=\alpha$, so (ii) holds with $\pi=K_{A}(0,0)$.

Now, assume (ii) holds; since $A$ is a determinate boundary condition function for $Q$ on $c_{1}, c_{2}, \cdots, \pi$ must be unique. Define $K_{A}$ on $[0, \infty) \times[0, \infty)$ as

$$
K_{A}(x, t)= \begin{cases}M(x, 0) \pi M(0, t) & \text { if } 0 \leqq t \leqq x \\ M(x, 0)[\pi-I] M(0, t) & \text { if } 0 \leqq x<t\end{cases}
$$

and let $R_{A}$ denote the integral operator with kernel $K_{A}$. Let $H$ be in $D_{0}$ and $b$ denote a positive number so that if $x>b, H(x)=0$. Define $U$ on $[0, \infty)$ as

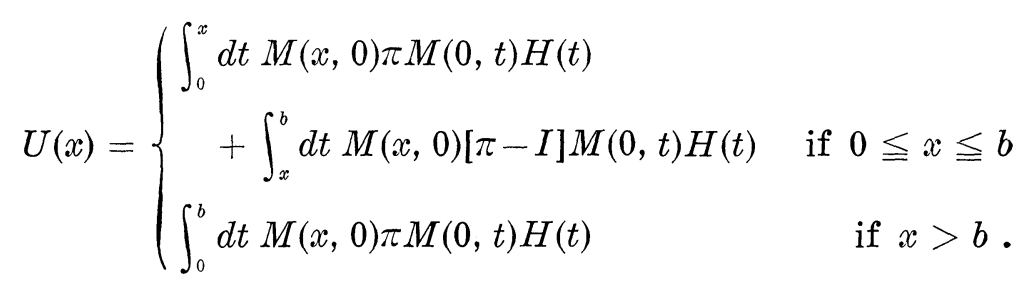

Differentiation yields that $U^{\prime}(x)-Q(x) U(x)=H(x)$ for each $x$ in $[0, \infty)$ and if $c_{n}>b$,

$$
\begin{aligned}
& A(0) U(0)+A\left(c_{n}\right) U\left(c_{n}\right) \\
= & T_{n}\left(\pi \int_{0}^{b} d t M(0, t) H(t)\right)-A(0) \int_{0}^{b} d t M(0, t) H(t) .
\end{aligned}
$$

By the definition of $\pi, \lim _{n \rightarrow \infty}\left[A(0) U(0)+A\left(c_{n}\right) U\left(c_{n}\right)\right]=0$ and so (i) holds.

For the remainder of the paper suppose that $A$ is a determinate boundary condition function for $Q$ on $c_{1}, c_{2}, \cdots$, condition (ii) in Theorem 2 holds and $K_{A}$ is defined on $[0, \infty) \times[0, \infty)$ by (2). (Condition (ii) is implied, for example, in case the sequence $\left\{T_{n}\right\}_{n=1}^{\infty}$ converges in norm to a regular element of $B$.) Let $D$ denote the set of continuous functions $H$ on $[0, \infty)$ such that $\int_{0}^{\infty} d t K_{A}(x, t) H(t)$ exists for each $x$ and furthermore, if $U$ is defined as

$$
U(x)=\int_{0}^{\infty} d t K_{A}(x, t) H(t) \quad \text { for } x \text { in }[0, \infty),
$$

then $U$ is a solution of boundary value problem (1) for the nonhomo- 
geneous term $H$. Let $R_{A}$ denote the integral operator with kernel $K_{A}$ and domain $D$; i.e., if $H$ belongs to $D$

$$
\left(R_{A} H\right)(x)=\int_{0}^{\infty} d t K_{A}(x, t) H(t) .
$$

Two aspects of the present development which differ from other treatments of Green's functions for singular boundary value problems are: (1) the Green's functions here are not necessarily square integrable in either place and (2) the domains of the associated integral inverting operators are not restricted to functions which are square integrable on $[0, \infty)$. However, the domain of $R_{A}$ does depend upon the problem, i.e., upon the particular $Q$ and $A$ involved. This dependence is the subject of the following two theorems.

Two sets of continuous function on $[0, \infty)$ which are relevant to the description of $D$ are defined as follows. Let $D_{1}$ denote the collection of continuous functions $H$ on $[0, \infty)$ for which there exists a solution of (1) for the nonhomogeneous term $H$. Let $D_{2}$ denote the collection of continuous functions $H$ on $[0, \infty)$ such that $\int_{0}^{\infty} d t(\pi-I) M(0, t)$ $H(t)$ exists.

It is clear that $D$ is a subset of the intersection of $D_{1}$ and $D_{2}$; not so obvious is the extent to which $D_{1} \cap D_{2}$ is contained in $D$.

Lemma. Suppose $H$ belongs to $D_{1} \cap D_{2}$; let $Y$ denote the solution of (1) for $H$ and let $X(x)=\int_{0}^{\infty} d t K_{A}(x, t) H(t)$ for all $x$ in $[0, \infty)$, then

$$
\begin{aligned}
T_{n}[Y(0)-X(0)]= & {\left[A(0) Y(0)+A\left(c_{n}\right) Y\left(c_{n}\right)\right] } \\
& +\left[A(0)-T_{n} \pi\right] \int_{0}^{c_{n}} d t M(0, t) H(t) \\
& -T_{n} \int_{c_{n}}^{\infty} d t(\pi-I) M(0, t) H(t)
\end{aligned}
$$

for each positive integer $n$.

Proof. Let $n$ denote a positive integer; property (iii) of the $M$ function provides that

$$
Y\left(c_{n}\right)=M\left(c_{n}, 0\right) Y(0)+M\left(c_{n}, 0\right) \int_{0}^{c_{n}} d t M(0, t) H(t),
$$

so

$$
\begin{aligned}
T_{n} Y(0) & =A(0) Y(0)+A\left(c_{n}\right) M\left(c_{n}, 0\right) Y(0) \\
& =A(0) Y(0)+A\left(c_{n}\right) Y\left(c_{n}\right)-A\left(c_{n}\right) M\left(c_{n}, 0\right) \int_{0}^{c_{n}} d t M(0, t) H(t) .
\end{aligned}
$$


Also,

$$
T_{n} X(0)=\left[A(0)+A\left(c_{n}\right) M\left(c_{n}, 0\right)\right] \int_{0}^{\infty} d t(\pi-I) M(0, t) H(t) .
$$

A straightforward computation provides the result of the lemma.

The domain $D$ of the inverting operator $R_{A}$ may be studied for the following three cases.

Case 1. There is an increasing sequence of positive integers $n_{1}$, $n_{2}, \cdots$ such that $T_{n_{i}}^{-1}$ exists for all $i$ and the transformation sequence $\left\{T_{n_{i}}^{-1}\right\}_{i=1}^{\infty}$ is uniformly norm bounded.

Case 2. There is an increasing sequence of positive integers $n_{1}$, $n_{2}, \cdots$ such that $T_{n_{i}}^{-1}$ exists for all $i$, but no subsequence of inverses is uniformly norm bounded.

Case 3. There is a positive integer $N$ such that if $n>N$, then $T_{n}^{-1}$ does not exist.

Note. Case 1 above is a sufficient condition for a function $A$ from $[0, \infty)$ into $B$ to be a determinate boundary condition function for $Q$ on $c_{1}, c_{2}, \cdots$.

Theorem 3. Suppose Case 1 above holds; if $H$ is in $D_{1} \cap D_{2}$ then $H$ is in $D$ if

$$
\lim _{i \rightarrow \infty}\left[A(0)-T_{n_{i}} \pi\right] \int_{0}^{c_{n_{i}}} d t M(0, t) H(t)=0 .
$$

Proof. By the lemma and existence of $T_{n_{i}}^{-1}$ for all $i$, we obtain in the notation of the lemma that

$$
\begin{aligned}
Y(0)-X(0)= & T_{n_{i}}^{-1}\left[A(0) Y(0)+A\left(c_{n_{i}}\right) Y\left(c_{n_{i}}\right)\right] \\
& +T_{n_{i}}^{-1}\left[A(0)-T_{n_{i}} \pi\right] \int_{0}^{c_{n_{i}}} d t M(0, t) H(t) \\
& -\int_{c_{n_{i}}}^{\infty} d t(\pi-I) M(0, t) H(t) \quad \text { for each } i .
\end{aligned}
$$

$H$ in $D_{2}$ provides that $\lim _{i \rightarrow \infty} \int_{c_{n_{i}}}^{\infty} d t(\pi-I) M(0, t) H(t)=0$ and $Y$ satisfies the asymptotic boundary condition so

$$
Y(0)-X(0)=\lim _{i \rightarrow \infty} T_{n_{i}}^{-1}\left[A(0)-T_{n_{i}} \pi\right] \int_{0}^{c_{n_{i}}} d t M(0, t) H(t) .
$$

Now, if $\lim _{i \rightarrow \infty}\left[A(0)-T_{n_{i}} \pi\right] \int_{0}^{c_{n_{i}}} d t M(0, t) H(t)=0$, then $Y(0)-X(0)=0$ 
and so $Y=X$, i.e., $X$ is the unique solution of (1) for $H$ and so $H$ is in the domain of $R_{A}$.

A subcase of Cases 1,2, and 3 above is that the transformation sequence $\left\{T_{n}\right\}_{n=1}^{\infty}$ be uniformly norm bounded, which occurs, for example, with $S=E_{2}$ and $T_{n}=\left[\begin{array}{ll}1 & 0 \\ 1 & 0\end{array}\right] n$ odd, $\left[\begin{array}{ll}0 & 1 \\ 0 & 1\end{array}\right]$ if $n$ is even.

THEOREM 4. Suppose $\left\{T_{n}\right\}_{n=1}^{\infty}$ is uniformly norm bounded; if $H$ is in $D_{1} \cap D_{2}$, then $H$ is in $D$ if and only if

$$
\lim _{n \rightarrow \infty}\left[A(0)-T_{n} \pi\right] \int_{0}^{c_{n}} d t M(0, t) H(t)=0 .
$$

Proof. Let $H$ denote a function in $D_{1} \cap D_{2}$; by the lemma

$$
\begin{aligned}
T_{n}[Y(0)-X(0)]= & {\left[A(0) Y(0)+A\left(c_{n}\right) Y\left(c_{n}\right)\right] } \\
& +\left[A(0)-T_{n} \pi\right] \int_{0}^{c} d t M(0, t) H(t) \\
& -T_{n} \int_{c_{n}}^{\infty} d t(\pi-I) M(0, t) H(t)
\end{aligned}
$$

for each positive integer $n$. Where $Y$ denotes the solution of (1) for $H$ and $X$ is defined on $(0, \infty)$ by

$$
X(x)=\int_{0}^{\infty} d t K_{A}(x, t) H(t) \quad x \text { in }[0, \infty) .
$$

$Y$ satisfies the asymptotic boundary condition so

$$
A(0) Y(0)+\lim _{n \rightarrow \infty} A\left(c_{n}\right) Y\left(c_{n}\right)=0 .
$$

The transformation sequence $\left\{T_{n}\right\}_{n=1}^{\infty}$ is uniformly norm bounded and $H$ is in $D_{2}$ so

$$
\lim _{n \rightarrow \infty} T_{n} \int_{c_{n}}^{\infty} d t(\pi-I) M(0, t) H(t)=0
$$

So

$$
\lim _{n \rightarrow \infty} T_{n}[Y(0)-X(0)]=\lim _{n \rightarrow \infty}\left[A(0)-T_{n} \pi\right] \int_{0}^{c_{n}} d t M(0, t) H(t) .
$$

The result of the theorem follows from $A$ being a determinate boundary condition function.

The following example illustrates the subcase for a Case 1 problem and shows that the domain of $R_{A}$ may be a proper subset of $D_{1} \cap D_{2}$. 
ExAmple. Let $c_{1}, c_{2}, \cdots$ denote a positive, increasing, unbounded number sequence. Consider the singular boundary value problem associated with the differential expression $L y=y^{\prime \prime}$ and the boundary condition function $A$ defined as

$$
A(x)= \begin{cases}{\left[\begin{array}{ll}
1 & 0 \\
0 & 2
\end{array}\right]} & \text { if } x=0, \\
{\left[\begin{array}{cc}
-1 /[1+\log (1+x)] & x /[1+\log (1+x)] \\
0 & -1
\end{array}\right]} & \text { if } x>0,\end{cases}
$$

We have $Q(x)=\left[\begin{array}{ll}0 & 1 \\ 0 & 0\end{array}\right]$ for $x \geqq 0, M(x, t)=\left[\begin{array}{cc}1 & x-t \\ 0 & 1\end{array}\right]$ for all numbers $x$ and $t$ and if $n$ is a positive integer,

$$
T_{n}=\left[\begin{array}{ll}
\log \left(1+c_{n}\right) /\left[1+\log \left(1+c_{n}\right)\right] & 0 \\
0 & 1
\end{array}\right] .
$$

So, $\lim _{n \rightarrow \infty} T_{n}=I=\left[\begin{array}{ll}1 & 0 \\ 0 & 1\end{array}\right]$ and $\pi=\left[\begin{array}{ll}1 & 0 \\ 0 & 2\end{array}\right] . A$ is a determinate boundary condition function for $Q$ on $c_{1}, c_{2}, \cdots$ and $K_{A}$ is calculated by equation (2).

Let $H(x)=\left[\begin{array}{l}0 \\ 1 /\left(1+x^{2}\right)\end{array}\right] x \geqq 0 . \quad H$ is in $D_{1}$ since the function $Y$ defined by

$$
Y(x)=\left[\begin{array}{l}
x \arctan x-\log +\left(1 x^{2}\right)^{1 / 2}+(\pi / 2) x-1 \\
\arctan x+\pi / 2
\end{array}\right]
$$

for $x \geqq 0$ is a solution of the singular boundary value problem with nonhomogeneous term $H$. Also, $\int_{0}^{\infty} d t(\pi-I) M(0, t) H(t)$ exists so $H$ is in $D_{2}$ and $\int_{0}^{\infty} d t K_{A}(x, t) H(t)$ exists for each $x \geqq 0$. The function $X$ defined by $X(x)=\int_{0}^{\infty} d t K_{A}(x, t) H(t)$ for $x \geqq 0$ does not satisfy the asymptotic boundary condition and so $H$ is in $D_{1} \cap D_{2}$ but not in the domain of $R_{A}$.

It remains to more completely describe how the domain of $R_{A}$ depends upon the problem and to investigate the complex numbers $\lambda$ for which one obtains an inverting operator $R(A, \theta, \lambda)$ for the singular boundary value problem

$$
\left\{\begin{array}{l}
Y^{\prime}-(Q+\lambda \theta) Y=H \\
A(0) Y(0)+\lim _{n \rightarrow \infty} A\left(c_{n}\right) Y\left(c_{n}\right)=0
\end{array}\right.
$$

where $\theta$ denotes a function from $[0, \infty)$ into $B$. 


\section{REFERENCES}

1. H. E. Benzinger, Green's functions on large intervals. Preliminary Report, Notices Amer. Math. Soc. 16 (1969), 114.

2. E. A. Coddington and N. Levinson, Theory of Ordinary Differeniial Equations, McGraw Hill Book Co., Inc., 1955.

3. J. W. Neuberger, Concerning boundary value problems, Pacific J. Math. 10 (1960), 1385- 1392.

4. A. J. Zettl, Quasi-Differential Operators in Hilbert Space, M. R. C. Technical Summary Report No. 845, 1968.

Received February 11, 1970. This paper is part of the author's doctoral dissertation which was directed by Professor John W. Neuberger.

WEST VIRGINIA UNIVERSITY 


\section{PACIFIC JOURNAL OF MATHEMATICS}

\section{EDITORS}

H. SAMELson

Stanford University

Stanford, California 94305

R. R. PHelPS

University of Washington

Seattle, Washington 98105
J. Dugundu

Department of Mathematics

University of Southern Californle

Los Angeles, California 9.0007

RICHARD ARENS

University of California

Los Angeles, California 9.0024

\section{ASSOCIATE EDITORS}
E. F. BECKENBACH
B. H. NeumanN
F. WOLE
K. Yoshida

\section{SUPPORTING INSTITUTIONS}

UNIVERSITY OF BRITISH COLUMBIA

CALIFORNIA INSTITUTE OF TECHNOLOGY

UNIVERSITY OF CALIFORNIA

MONTANA STATE UNIVERSITY

UNIVERSITY OF NEVADA

NEW MEXICO STATE UNIVERSITY

OREGON STATE UNIVERSITY

UNIVERSITY OF OREGON

OSAKA UNIVERSITY

UNIVERSITY OF SOUTHERN CALIFORNIA

\author{
STANFORD UNIVERSITY \\ UNIVERSITY OF TOKYO \\ UNIVERSITY OF UTAH \\ WASHINGTON STATE UNIVERSITY \\ UNIVERSITY OF WASHINGTON \\ AMERICAN MATHEMATICAL SOCIETY \\ CHEVRON RESEARCH CORPORATION \\ NAVAL WEAPONS CENTER
}

The Supporting Institutions listed above contribute to the cost of publication of this Journal, but they are not owners or publishers and have no responsibility for its content or policies.

Mathematical papers intended for publication in the Pacific Journal of Mathematics should be in typed form or offset-reproduced, (not dittoed), double spaced with large margins. Underline Greek letters in red, German in green, and script in blue. The first paragraph or two must be capable of being used separately as a synopsis of the entire paper. The editorial "we" must not be used in the synopsis, and items of the bibliography should not be cited there unless absolutely necessary, in which case they must be identified by author and Journal, rather than by item number. Manuscripts, in duplicate if possible, may be sent to any one of the four editors. Please classify according to the scheme of Math. Rev. Index to Vol. 39. All other communications to the editors should be addressed to the managing editor, Richard Arens, University of California, Los Angeles, California, 90024.

50 reprints are provided free for each article; additional copies may be obtained at cost in multiples of 50 .

The Pacific Journal of Mathematics is published monthly. Effective with Volume 16 the price per volume (3 numbers) is $\$ 8.00$; single issues, $\$ 3.00$. Special price for current issues to individual faculty members of supporting institutions and to individual members of the American Mathematical Society: $\$ 4.00$ per volume; single issues $\$ 1.50$. Back numbers are available.

Subscriptions, orders for back numbers, and changes of address should be sent to Pacific Journal of Mathematics, 103 Highland Boulevard, Berkeley, California, 94708.

PUBLISHED BY PACIFIC JOURNAL OF MATHEMATICS, A NON-PROFIT CORPORATION

Printed at Kokusai Bunken Insatsusha (International Academic Printing Co., Ltd.), 7-17, Fujimi 2-chome, Chiyoda-ku, Tokyo, Japan. 


\section{Pacific Journal of Mathematics}

\section{Vol. 36, No. 2 December, 1971}

George E. Andrews, On a partition problem of H. L. Alder ............ 279

Thomas Craig Brown, An interesting combinatorial method in the theory of locally finite semigroups .......................... 285

Yuen-Kwok Chan, A constructive proof of Sard's theorem ............. 291

Charles Vernon Coffman, Spectral theory of monotone Hammerstein

operators...................................... 303

Edward Dewey Davis, Regular sequences and minimal bases .......... 323

Israel (Yitzchak) Nathan Herstein and Lance W. Small, Regular elements in

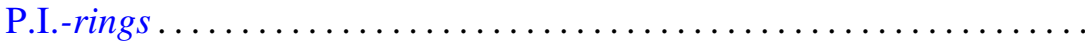

Marcel Herzog, Intersections of nilpotent Hall subgroups ..............

W. N. Hudson, Volterra transformations of the Wiener measure on the space

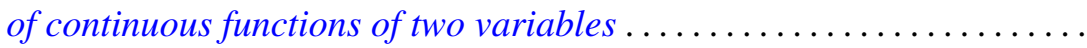

J. H. V. Hunt, An n-arc theorem for Peano spaces ................ 351

Arnold Joseph Insel, A decomposition theorem for topological group

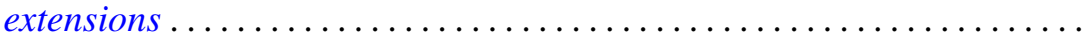

Caulton Lee Irwin, Inverting operators for singular boundary value

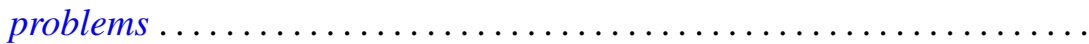

Abraham A. Klein, Matrix rings of finite degree of nilpotency ............ 387

Wei-Eihn Kuan, On the hyperplane section through a rational point of an algebraic variety...

John Hathway Lindsey, II, On a six-dimensional projective representation of $\mathrm{PSU}_{4}(3)$

Jorge Martinez, Approximation by archimedean lattice cones ...

J. F. McClendon, On stable fiber space obstructions .........

Mitsuru Nakai and Leo Sario, Behavior of Green lines at the Kuramochi boundary of a Riemann surface ....................

Donald Steven Passman, Linear identities in group rings. I. .

Donald Steven Passman, Linear identities in group rings. II ...

David S. Promislow, The Kakutani theorem for tensor products of

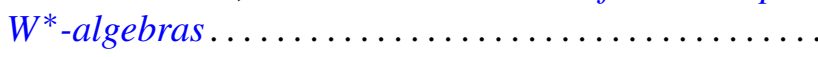

Richard Lewis Roth, On the conjugating representation of a finite group

Bert Alan Taylor, On weighted polynomial approximation of entire functions...

William Charles Waterhouse, Divisor classes in pseudo Galois

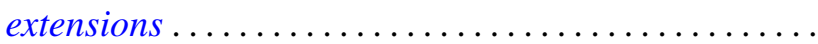

Chi Song Wong, Subadditive functions ...

Ta-Sun $\mathrm{Wu}$, A note on the minimality of certain bitransformation groups 